\title{
Cost-effectiveness of nurse-led self-help for recurrent depression in the primary care setting: design of a pragmatic randomised controlled trial
}

Karolien EM Biesheuvel-Leliefeld ${ }^{1 *}$, Sandra MA Kersten ${ }^{1}$, Henriette E van der Horst ${ }^{1}$, Anneke van Schaik², Claudi LH Bockting ${ }^{3}$, Judith E Bosmans ${ }^{4}$, Filip Smit ${ }^{5,6}$ and Harm WJ van Marwijk ${ }^{1}$

\begin{abstract}
Background: Major Depressive Disorder is a leading cause of disability, tends to run a recurrent course and is associated with substantial economic costs due to increased healthcare utilization and productivity losses. Interventions aimed at the prevention of recurrences may reduce patients' suffering and costs. Besides antidepressants, several psychological treatments such as preventive cognitive therapy (PCT) are effective in the prevention of recurrences of depression. Yet, many patients find long-term use of antidepressants unattractive, do not want to engage in therapy sessions and in the primary care setting psychologists are often not available. Therefore, it is important to study whether PCT can be used in a nurse-led self-help format in primary care. This study sets out to test the hypothesis that usual care plus nurse-led self-help for recurrent depression in primary care is feasible, acceptable and cost-effective compared to usual care only.
\end{abstract}

Design: Patients are randomly assigned to 'nurse-led self-help treatment plus usual care' (134 participants) or 'usual care' (134 participants). Randomisation is stratified according to the number of previous episodes ( 2 or 3 previous episodes versus 4 or more). The primary clinical outcome is the cumulative recurrence rate of depression meeting DSM-IV criteria as assessed by the Structured-Clinical-Interview-for-DSM-IV- disorders at one year after completion of the intervention. Secondary clinical outcomes are quality of life, severity of depressive symptoms, co-morbid psychopathology and self-efficacy. As putative effect-moderators, demographic characteristics, number of previous episodes, type of treatment during previous episodes, age of onset, self-efficacy and symptoms of pain and fatigue are assessed. Cumulative recurrence rate ratios are obtained under a Poisson regression model. Number-needed-tobe-treated is calculated as the inverse of the risk-difference. The economic evaluation is conducted from a societal perspective, both as a cost-effectiveness analysis (costs per depression free survival year) and as a cost-utility analysis (costs per quality adjusted life-year).

Discussion: The purpose of this paper is to outline the rationale and design of a nurse-led, cognitive therapy based self-help aimed at preventing recurrence of depression in a primary care setting. Only few studies have focused on psychological self-help interventions aimed at the prevention of recurrences in primary care patients.

Trial registration: NTR3001 (www.trialregister.nl)

Keywords: Major depressive disorder, relapse, recurrence, prevention, cognitive therapy, primary care, randomised controlled trial, design

\footnotetext{
* Correspondence: k.leliefeld@vumc.nl

'Department of General Practice and the EMGO + Institute for Health and Care Research (EMGO+), VU University medical Centre, Amsterdam, The Netherlands

Full list of author information is available at the end of the article
} 


\section{Background}

\section{Recurrent major depressive disorder}

Major Depressive Disorder (MDD) is a leading cause of disease burden and is associated with significant healthcare costs and costs stemming from productivity losses $[1,2]$. MDD's disease burden stems largely from its recurrent nature [3]. Each additional depressive episode increases the risk of recurrence by $18 \%$ [4]. Interventions aimed at the prevention of recurrences in recovered patients may significantly reduce the burden of depression [3]. Up till now, maintenance treatment has been largely based on antidepressants (AD). However, the evidencebase to support such prolonged treatment is poor [5-8] and moreover there is no evidence when to stop AD since most studies restricted their follow up to no longer than 2 years [9]. Furthermore, many depressed patients prefer psychological treatments to drugs [10] and many are not willing to take $\mathrm{AD}$ for prolonged periods of time $[11,12]$. Also, adherence in $\mathrm{AD}$ users is estimated at only $50 \%$ at best [11-13]. As such, there is a need for an accessible alternative to maintenance treatment with AD. Psychological interventions might offer an interesting alternative to prevent recurrence of MDD in recovered patients.

\section{Terminology}

At this point it might be well to introduce some terminology. MDD tends to run a relapsing and recurrent course. Both relapse and recurrence refer to the reappearance of a full-blown MDD after a symptom-free period. The essential distinction between both terms is the time at which each event occurs (Figure 1 [14]). According to the description by Frank et al. [15], relapse is defined as 'a return of symptoms satisfying full syndrome criteria for an episode that occurs during a period of remission, but before recovery'. As for recurrence, this is defined as 'the appearance of a new episode of MDD, occurring during recovery'. Conceptually, this represents the beginning of a new episode of an illness. Treatment stages can be defined accordingly: following remission and before recovery 'continuation treatment' is offered. Following recovery, treatment enters the maintenance stage. Both treatments have the aim to prevent recurrences.

For research purposes a consensus definition recommends that a 6-month threshold is justifiable to distinct between remission and recovery because of the median duration of MDD [15]. In patients experiencing relapsing/ recurring MDD however, this threshold can be debated because of the mostly shorter duration of an episode. In this trial no distinction is made between relapse and recurrence (henceforth called 'recurrence') nor between remission and recovery (henceforth 'recovery'), nor between continuation and maintenance treatment (henceforth 'maintenance treatment'). Exact definitions and cut-off points of all terms with respect to this trial are handled in detail later (see 'Eligibility of participants').

\section{Efficacy of psychological interventions}

The literature shows that psychological interventions may offer a good alternative or a welcome adjunct to AD. Hollon et al. (2010) concluded in their review that Cognitive Behavioural Therapy (and especially CT) is as efficacious as medications in the treatment of MDD and that $\mathrm{CT}$ has an enduring effect that protects against subsequent relapse and possibly recurrence regardless of when it is applied [17]. Continuation/maintenance CT has been found to reduce risk for relapse/recurrence in MDD in a trial of Jarrett et al. (2001) [18]. A meta-analysis by Vittengl et al. (2007), including 28 studies and comprising 1,880 adults, demonstrated that among acute-phase treatment responders, continuation of $\mathrm{CBT}$ compared to assessment only or clinical management, reduced the number of recurrences substantially from $73 \%$ to $40 \%$, over a mean of 153 weeks follow-up [19]. Specific protocols based on CBT have been developed for the prevention of

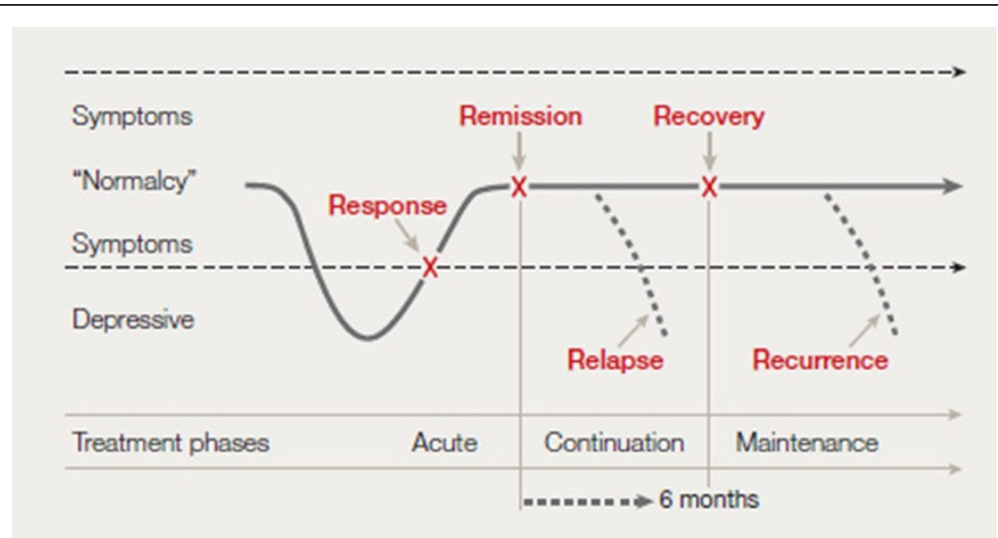

Figure 1 Overview of response, remission, recurrence, and relapse in relation to the treatment phase [14]. Modified after Tohen et al. (2009) [16] @ 2009 Blackwell Munksgaard 
depression, such as Preventive Cognitive Therapy (PCT). For patients with a history of 4 or more depressive episodes, $75 \%$ receiving PCT experienced a recurrence over a period of 5,5 years versus $95 \%$ receiving usual care [20]. PCT targets underlying cognitive vulnerability factors, such as dysfunctional cognitions that are easily reactivated in recovered patients and therefore may cause vulnerability for recurrence. The treatment focuses on identifying and changing these vulnerability factors, while at the same time reinforcing specific memories of positive experience by keeping a diary of positive experiences and formulating specific recurrence prevention strategies [21].

\section{The case for guided self-help}

In the Netherlands, evidence-based psychological treatments are less readily accessible in primary care [10] because they require specific expertise, extensive training and draw on scarce resources. Furthermore, reimbursement of psychological treatments in primary care through insurance is becoming limited. Because the vast majority of persons with a high risk of developing a new episode visits - and receives treatment from - their own primary care physician (PCP), this seems to be the most appropriate coordinator of preventive interventions [22]. These interventions should be cost-effective, readily accessible at the primary care or community level, acceptable for patients and health care providers, and should easily be integrated into current care.

Self-help interventions using self-help books (bibliotherapy) are one of the most accessible forms of psychological interventions for primary care patients. Research indicates that self-help has a moderate to large effect in reducing symptoms of depression and anxiety [23-26]. PCT can easily be transformed into a self-help intervention because of its structured design. Some form of support however, should be provided to enhance patients' compliance, which in turn is associated with better treatment response overall [26-29]. There is growing evidence that mental health nurses or social workers can effectively deliver self-help treatment protocols for depression, particularly in chronic care models [30,31]. For both economic and pragmatic reasons it is attractive to let nurses play a pivotal and facilitating role in the provision of PCT instead of a psychologist.

\section{Objectives}

The primary objective of this study is to evaluate whether nurse-led, cognitive treatment based self-help in addition to usual care is cost-effective in preventing recurrences for patients at high risk of recurrent MDD in primary care compared to usual care alone. Furthermore, this study examines whether the addition of nurse-led self-help to usual care for patients with recurrent MDD is effective in improving health related quality of life, in reducing comorbid distress, anxiety and/or somatisation, in improving self-efficacy and meets with patients' satisfaction. Finally, we examine which socio-demographic and clinical variables (e.g. pain and fatigue) moderate treatment response.

\section{Design}

This study is a multi-site, pragmatic randomised controlled trial among primary care patients with recurrent MDD who are currently recovered. Patients are recruited through primary care practices and are randomly assigned to two parallel groups: 'nurse-led self-help treatment plus usual care' (134 patients) or 'usual care alone' (134 patients). A flowchart is shown in Figure 2. It is not possible to blind neither patients nor healthcare providers to the intervention in this study due to the nature of this self-help intervention.

\section{Eligibility of participants}

Patients are eligible for participation in the trial when they: 1) are between 18 and 65 years old, 2) have had at least 2 previous depressive episodes 3) are currently recovered, 4) are fluent in reading and speaking Dutch and 5) have access to the internet. Criterion for 'currently recovered' includes 'no diagnose of depression according to the Structured Clinical Interview for DSMIV (SCID-I)' [32]. The recovered episode should last for longer than 8 weeks and no longer than 2 years.

Participants who have current (hypo) mania or a history of bipolar disease, any current organic brain disorder, psychotic disorder or severe sensory disabilities are excluded. Patients who have drug or alcohol related abuse or dependence as main diagnosis are also excluded. These exclusion criteria are checked in patient files.

\section{Recruitment}

The PCP screens for eligible patients by searching the database of the primary care practice using the following indicators [33]: antidepressants prescription, strong free text indication of depression or a history of depression according to the International Classification of Primary Care (ICPC) codes in the PCP's patient files. Subsequently, the PCP approaches potentially eligible patients with global information about the study, contact information and a global screening form comprising three questions: 1) did you experience 2 or more depressive episodes? 2) are you currently recovered? and 3) did the last episode end longer than 8 weeks- and no longer than 2 years ago?. If a patient is eligible for the trial based on the global screening and if the patient agrees upon receiving more information, he is sent an extensive study information letter and an informed consent form for participation in the trial. Consenting patients are assessed for their eligibility in more detail using the SCID-I. Eligible patients who sign informed consent enter the trial. 


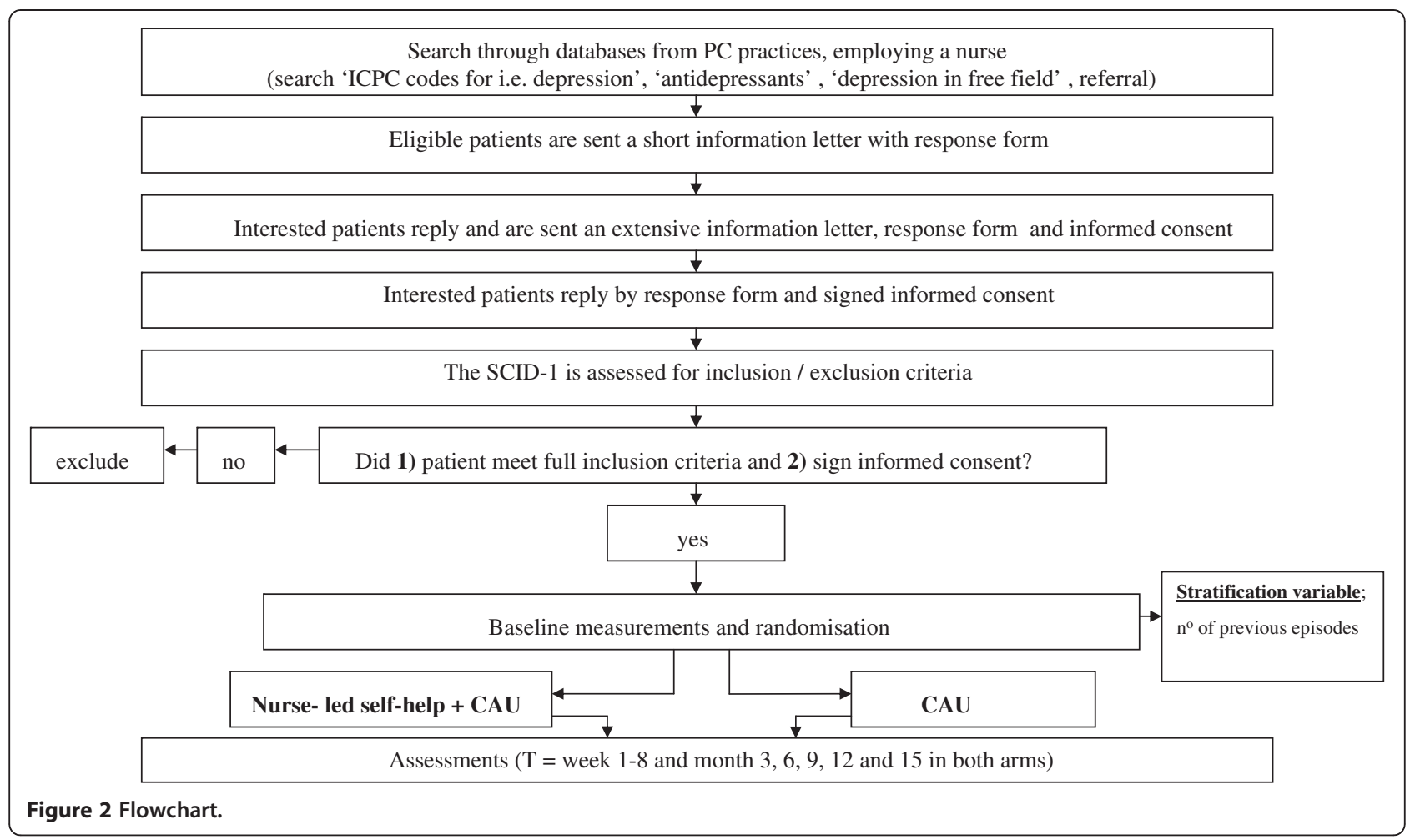

\section{The intervention \\ Self-help}

The intervention consists of nurse-led self-help treatment based on PCT $[21,34]$. Patients are offered a selfhelp book including background literature for further reading and assignments. This self-help book enables patients to follow the treatment in the privacy of their own homes and at a pace that suits them best. The treatment consists of eight weekly modules with a fixed structure and it takes approximately 1.5 hour each week to complete the assignments. Additionally, patients fill out the electronic Q-IDS-SR weekly to monitor the severity of their depressive symptoms.

\section{Nurse-led support}

The nurse lends minimal support to help patients work through the self-help intervention. Prior to the start of the treatment, a face-to-face meeting with the nurse (with a maximum duration of 30 minutes) is planned at the primary care practice. This meeting involves a discussion of current symptoms, motivational interviewing, psychoeducation on the course and treatment of recurrent depression and an introduction to the nurse-led self-help treatment on the basis of the self-help book. Afterwards, the self-help treatment starts and eight weekly telephone contacts (at a maximum of 15 minutes) follow, initiated by the nurse. During these telephone contacts the nurse explores how the patient fares with the self-help treatment according to a strict protocol. In the weekly contacts the nurse asks the following questions: 1) did the patient fill out the electronic Q-IDS-SR questionnaire? 2) did the patient read and understand the literature belonging to that week? 3) did the patient complete the accompanying assignments? and 4) what difficulties did the patient experience in his assignments? After answering these questions, patients are shortly introduced to next week's literature and exercises. The contact is supportive, activating and facilitating and the nurse does not engage in a therapeutic relationship with the patient. If a nurse notices the emergence of depressive symptoms during a regular phone-contact or a patient brings up feeling depressed, the nurse emphasizes specific parts of the treatment that may help the patient to better cope with these symptoms in order to prevent recurrence. If a patient expresses suicidal thoughts the PCP is notified immediately. After each contact the nurse summarizes the conversation (including the questions) in an electronic journal using a checklist. This journal is a way to both monitor and promote treatment integrity on the side of the patient (did the patient read and apply the literature) and the nurse (did the nurse go through all the questions).

\section{Training and supervision of nurses}

The mental health nurse attends an one-day training, during which attention is paid to the protocol and content of PCT and to guiding a self-help treatment. The nurse is also taught to let recovered patients deal with symptoms. Since participating nurses already have experience with 
cognitive therapy, an one-day training is sufficient. The training is delivered by two trained psychologist. To detect adherence and/or competence issues, audiotaped telephone contacts with two patients are evaluated during supervision sessions for each nurse, before the actual start of the trial. During the trial, nurses can contact their supervisors at any time for additional questions and feedback.

\section{Usual care}

In both treatment conditions, treatment as usual involves usual care (i.e. standard/routine treatment, including no treatment) as typically provided by the $\mathrm{PCP}$ according to the Dutch PCP clinical guidelines (NHG-guidelines) [35]. These guidelines recommend continuation of treatment with $\mathrm{AD}$, preventive psychological treatment or both, depending on the distress, level of dysfunctioning, psychological or physical co-morbidity and preferences of the patient.

In this trial, usual care is not restricted during the period from entry to end of follow-up. By adding no restrictions to usual care, the findings of this study are more generalisable. There usually is some inter-practice variation in treatment despite the clinical guidelines. It is therefore important to obtain a clear understanding of what (additional) treatments are received by patients in both arms of the trial. To that end, data is collected on health care utilization, using the TiC-P [36] - the most commonly used health care receipt interview in the Netherlands (see below for more details on the measurements) and the Medication Adherence Questionnaire (MAQ) [37]. As the use of usual care in both arms in this trial brings the risk of behavioural change by caregivers and patients because of the information that is supplied [38], minimum information is supplied to any participating person (see Discussion for further details).

\section{Sample size}

To calculate the sample size of the intervention and control group, we combined rudimentary findings from previous randomised controlled trials (RCT's), which resulted in a mean recurrence rate of $33 \%$ after 2 years of follow-up versus $67 \%$ in the control group (active and non-active control). Based on this we assume a risk reduction of $20 \%$ rate in this study between the two conditions. To detect this $20 \%$ risk reduction in a 2 -sided test at alpha $=0.05$ and a power of 1-beta $=0.80,107$ patients in each condition are required. Compensating for loss to follow-up of $20 \%$ over the whole 15 months follow-up, requires $(107 / 0.8=) 134$ participants at baseline in each trial arm.

\section{Randomisation}

Patients who are eligible for the trial and who have given their informed consent, are randomised to 'nurse-led selfhelp treatment plus usual care' or 'usual care alone'. An independent researcher performs randomisation centrally (Random Allocation Software version 1.0.0), using a blocked randomisation scheme with blocks of 2 patients. The researchers receive the participant's number and automatically random generated condition in the trial by email. Randomisation is pre-stratified for the number of previous depressive episodes ( 2 or 3 episodes versus 4 or more episodes). The rationale for stratification based on this variable is that several subgroup analyses suggest that PCT is more effective in 'high risk' patients, meaning patients with a history of 4 or more episodes on a lifetime basis $[21,39,40]$.

\section{Outcome measurements}

For an overview of assessments at baseline, during the intervention and during follow-up, see Table 1. The primary researcher $(\mathrm{KB})$ conducts collection and analysis of the data with help of a research assistant (SK).

\section{Demographics}

At baseline the socio-demographic characteristics of participants are collected (age, gender, educational level, marital status, etc.). The number and duration of previous depressive episodes, age of onset of first depressive episode and kind of treatments received are also assessed at baseline.

\section{Primary outcome}

The primary clinical outcome is the cumulative recurrence rate of depression meeting DSM-IV criteria for a major depressive episode [49]. Recurrence of depression

\section{Table 1 overview of assessments}

\begin{tabular}{|c|c|c|c|c|c|c|c|c|}
\hline Measure & Description & T0 & w1,8 & T1 & T2 & T3 & T4 & T5 \\
\hline \multicolumn{9}{|l|}{ Interviews } \\
\hline SCID-I [32] & $\begin{array}{l}\text { DSM-IV Axis I } \\
\text { Disorders }\end{array}$ & + & & + & + & + & + & + \\
\hline \multicolumn{9}{|c|}{ Self-report measures } \\
\hline Q-IDS-SR [41] & $\begin{array}{l}\text { Depressive } \\
\text { symptoms }\end{array}$ & + & + & + & + & + & + & + \\
\hline EQ-5D [42] & Quality of life & + & & + & + & + & + & + \\
\hline SF-12 [43] & Quality of life & + & & + & + & + & + & + \\
\hline TIC-P [36] & $\begin{array}{l}\text { Direct/indirect } \\
\text { costs }\end{array}$ & + & & + & + & + & + & + \\
\hline 4DSQ [44] & $\begin{array}{l}\text { Comorbid } \\
\text { psychopathology }\end{array}$ & + & & & & + & & + \\
\hline $\begin{array}{l}\text { General self- } \\
\text { efficacy scale [45] }\end{array}$ & Self-efficacy & + & & & & + & & + \\
\hline FSS[46] & Severity of fatigue & + & & & & & & \\
\hline MPQ-DLV[47] & $\begin{array}{l}\text { Severity/evaluation } \\
\text { of pain }\end{array}$ & + & & & & & & \\
\hline MAQ [37] & $\begin{array}{l}\text { Medication } \\
\text { Adherence }\end{array}$ & + & & + & + & + & + & + \\
\hline CSQ-8 [48] & Satisfaction & & & & & & & + \\
\hline
\end{tabular}

T0 $=$ baseline, $\mathrm{w} 1,8=$ week $1-8, \mathrm{~T} 1=3$ months, $\mathrm{T} 2=6$ months, $\mathrm{T} 3=9$ months, $\mathrm{T} 4=12$ months, $\mathrm{T} 5=15$ months. 
(current or since the last assessment point) is assessed in both arms with the SCID-I [32] at 3, 6, 9, 12 and 15 months follow-up by a trained researcher and research assistant. Interviews are randomly audiotaped and evaluated for integrity reasons. The incidence rate in the intervention group is compared to the incidence rate in the control group and thus expressed as the (cumulative) incidence rate ratio.

\section{Secondary outcomes}

Secondary clinical outcomes include health related quality of life (measured with both the 'EuroQol' (EQ-5D)[42] and 'Short Form-12' (SF-12)[43]), severity of depressive symptoms (measured with the Q-IDS-SR [41]), co-morbid distress, anxiety and somatisation (measured with the 'Four Dimension Symptom Questionnaire', 4-DSQ [44]) and self-efficacy (measured with the 'General Self Efficacy Scale, GSES [45]). Quality adjusted life years (QALY's) are calculated based on both the EuroQol [42] and SF-12 [43], using the Dutch tariff estimated by Lamers et al. [50] and using Brazier's algorithm [51], respectively. All secondary clinical outcomes are measured at baseline and at 9 and 15 months follow-up.

\section{Putative effect-moderators}

Several risk factors for recurrent depression have been identified [52] and may also be relevant for predicting treatment response. These risk factors include non-adherence, demographic factors such as age and gender, high number and longer duration of previous episodes, younger age at the onset of the first depressive episode [53], presence of residual symptoms [54], low socioeconomic status [55], low self-efficacy for managing depression [55] and also symptoms of pain [56] and fatigue [57] appear to be risk indicators for imminent recurrence of depression. The type of treatment received during previous depressive episodes (psychological intervention/AD/no care) may also be relevant for treatment response. Patients who already had a psychological intervention may have the benefit of possible long-term protection for recurrence [58]. All of these factors are therefore assessed as putative effect-moderators.

\section{Cost measures}

Cost-effectiveness is evaluated from a societal perspective meaning that the costs of the intervention, other health care utilization costs, patients' out-of-pocket costs and costs due to productivity losses are included in the economic evaluation. Health care utilization is measured using the TiC-P [36] at baseline and 3, 6, 9, 12 and 15 months follow-up. Medical costs that are assessed include costs related to the intervention, medication use, hospital admissions, and contacts with other healthcare professionals. For the valuation of health care utilization, standard prices published in the Dutch costing guidelines are used [59].
Medication use is valued using prices of the Royal Dutch Society for Pharmacy, including the costs of prescription by the $\mathrm{PCP}$ and the pharmacist's dispensing costs. A cost price for the nurse-led self-help intervention is calculated using a bottom-up approach and will account for costs for personnel, patient materials and rental of practice spaces. Costs and effects exceeding 12 months follow-up are discounted, in accordance with the Dutch guideline for economic evaluation in health care [60]. Costs of productivity losses are estimated using the friction cost method [61]. In a secondary analysis, the human capital method is used to estimate productivity losses.

\section{Analyses of clinical outcomes}

Standard descriptive methods (e.g. frequencies, percentages and means) are used to summarize the demographic and clinical features of the intervention and control group and to check whether the randomisation has resulted in a wellbalanced design.

Analyses are conducted according to the intention-totreat principle, meaning that all patients who have been randomised are included in the analyses. Missing endpoints are imputed using the Expectation-Maximization (EM) algorithm. To gauge the robustness of the outcomes, this analysis is repeated while using a Multiple-Imputation (MI) approach. All tests are conducted at $\mathrm{P}<0.05,2$-tailed. Additional completer analyses for all patients that attended at least $80 \%$ of the telephone sessions are performed.

\section{Analysis of primary outcome}

Cumulative recurrence rate ratios are estimated using a Poisson regression model. Number-needed-to-be-treated (NNT) is calculated as the inverse of the risk difference (RD) which is estimated using a linear probability model. Data-analysis takes into account that data are clustered within primary care practices and patients. The nested data structure entails violation of the usual assumption that data are uncorrelated. Therefore, all analyses are design-based, taking the clustered data structure into account, using Stata’s [62] procedures for clustered data [63].

\section{Analysis of secondary outcomes}

The effect of the self-help treatment on health related quality of life, symptom severity, co-morbid distress, anxiety and/or somatisation and self-efficacy is analysed by regressing these secondary endpoints with the randomisation condition, while correcting for baseline values.

\section{Analysis of effect-moderation}

Moderator analyses are conducted for socio-demographic and clinical variables. Subgroups that show particularly good response to the intervention are identified by regressing $(P<0.05)$ depression severity (measured with Q-IDSSR) on the interaction term of treatment and baseline 
characteristics of the patients, namely number of previous depressive episodes, previous and current treatment, age of onset of first depression, self-efficacy in managing depression, symptoms of pain and fatigue and sociodemographic characteristics like gender, marital status, age and socio-economic status.

\section{Analysis of economic data}

Missing cost- and effect data are imputed using multiple imputation according to the MICE algorithm developed by van Buuren [64]. Costs typically have a highly skewed distribution. Policy makers want to have information on the difference in mean total costs between the two treatment groups in order to estimate the total health care budget needed for a specific condition [65]. Therefore, bias-corrected and accelerated bootstrapping with 5000 replications is used to estimate $95 \%$ confidence intervals around the mean difference in total costs between the treatment groups.

Both a cost-effectiveness analysis (CEA, with depressionfree person years as the clinical end term) and as a costutility analysis (CUA, with incremental costs per quality adjusted life years (QALY) gained as the clinical end-term) are performed. Bootstrapping is used to estimate the uncertainty surrounding the incremental cost-effectiveness ratios (ICERs) which are graphically presented on costeffectiveness planes. Cost-effectiveness acceptability curves and net monetary benefits are also estimated [66].

An incremental net benefit regression (INBR) analysis is conducted to address the research question in which groups the intervention is likely to be particularly costeffective, analogous to the moderator analyses for clinical endpoints. The same set of variables is used in these INBR analyses. The incremental net benefit is calculated as $E \lambda-C$. The first term is the number of units of effectiveness gained in the intervention group in comparison with the control group multiplied by the amount $(\lambda)$ society is willing to pay (WTP) for a unit of effect gained. Because $\lambda$ is unknown, we use a likely WTP-range. The product term is subtracted by the difference in costs between the groups yielding the net benefit expressed in monetary terms. Incremental netbenefits are analysed using a regression analysis approach [67] and helps to identify sub-groups for which the intervention is particularly cost-effective.

\section{Patients' satisfaction}

At 15 months patients' satisfaction is assessed using the Client Satisfaction Questionnaire (CSQ-8) [48] in both the intervention and control group. Additionally, 20 'experimental' patients who responded best, and 20 'experimental' patients who responded worst in terms of recurrences are approached for an in-depth (qualitative) interview. Comparing responses from both groups may help to increase understanding what aspects of the intervention must change or remain intact.

\section{Discussion}

Given its recurrent character, new minimal interventions are needed to prevent new episodes of MDD. As patients with recurrent MDD account for great societal costs, an intervention to prevent recurrence in the maintenance phase will potentially lead to great reduction in health care utilization and costs of absenteeism and presenteeism. This is as far as we are aware of, the first study that examines the cost-effectiveness of a nurse-led, cognitive treatment based self-help for patients with recurrent MDD in primary care. This innovative selfhelp format ensures that patients can complete the treatment in their own time and at their own homes, which makes it easy accessible. Besides, being led by nurses, the treatment is expected to be economically affordable and sustainable.

The effect of several socio-demographic and clinical variables on treatment response is assessed. This might lead to insights that will lead to the development of more targeted interventions.

The RCT-design of this trial is considered the ultimate test of a medical hypothesis, and is the support of evidence-based medicine. By adding no restrictions to usual care in this RCT, the findings of this study will be more generalisable.

Risks for adverse events in patients in the intervention arm are very low due to the psychological character of the intervention and because there is no restriction to usual care. In the case of a patient expressing suicidal thoughts, the PCP is notified. These procedures are made explicit in the informed consent papers and protocols.

A limitation of this trial is that there might not be a big contrast in primary outcome (cumulative rate of recurrence) between the 2 arms of the trial at the end of follow-up, because both arms include usual care. Another limitation is, as in any trial that involves psychological treatment, that it is not possible, due to the design of the intervention, to blind patients, health care providers and researchers to the patient's randomised condition. Therefore it is not possible to prevent any behavioural change during the course of the trial. Patients' behaviour in the control arm might be influenced by reading the study information letter and a PCP's choice regarding usual care might be influenced by the knowledge of a patient starting the intervention. Nurses might be influenced in their support for patients when guiding the self-help treatment because of their knowledge of the patients' additional care. The information given to PCP's, nurses and patients in both arms is therefore limited to a minimum to overcome this limitation. 


\section{Competing interest}

The authors declare that they have no competing interests.

\section{Acknowledgements}

This study is funded by ZonMW, the Netherlands Organisation for Health Research and Development.

\section{Author details}

'Department of General Practice and the EMGO + Institute for Health and Care Research (EMGO+), VU University medical Centre, Amsterdam, The Netherlands. ${ }^{2}$ Department of Psychiatry and the EMGO + Institute for Health and Care Research (EMGO+), VU University Medical Centre, Amsterdam, The Netherlands. ${ }^{3}$ Department of Clinical Psychology, Groningen University, Groningen, The Netherlands. ${ }^{4}$ Department of Health Sciences and EMGO + Institute for Health and Care Research, Faculty of Earth and Life Sciences, VU University Amsterdam, Amsterdam, The Netherlands. ${ }^{5}$ Department of Public Mental Health, Trimbos Institute (Netherlands Institute of Mental Health and Addiction), Utrecht, The Netherlands. ${ }^{6}$ Department of Epidemiology and Biostatistics, EMGO + Institute for Health and Care Research, VU University Medical Centre, Amsterdam, The Netherlands.

\section{Authors' contributions}

$\mathrm{KB}$ and $\mathrm{SK}$ drafted this paper which was added to and modified by $\mathrm{HvdH}_{\text {, }}$ $A v S, J B, F S, C B$, and HVM. CB modified the content of PCT to the content of the nurse-led self-help treatment. $\mathrm{KB}, \mathrm{CB}, \mathrm{HvdH}$, AvS, FS and HvM contributed to the design of the study and JB, FS and KB contributed to the analytic strategy. All authors read and approved the final manuscript.

\section{Ethical principles}

The study protocol was approved by the Ethics Committee of the VU University Medical Centre and will be conducted according to the principles of the Declaration of Helsinki (version 2004) and the Medical Research Involving Human Subjects Act (WMO).

Received: 13 February 2012 Accepted: 7 June 2012

Published: 7 June 2012

\section{References}

1. Murray CJ, Lopez AD: Regional patterns of disability-free life expectancy and disability-adjusted life expectancy: global Burden of Disease Study. Lancet 1997, 349:1347-1352.

2. Ormel J, Petukhova M, Chatterji S, Aguilar-Gaxiola S, Alonso J, Angermeyer MC, Bromet EJ, Burger H, Demyttenaere K: de GG et al.: Disability and treatment of specific mental and physical disorders across the world. $B$ J Psychiatry 2008, 192:368-375.

3. Vos T, Haby MM, Barendregt JJ, Kruijshaar M, Corry J, Andrews G: The burden of major depression avoidable by longer-term treatment strategies. Arch Gen Psychiatry 2004, 61:1097-1103.

4. Mueller TI, Leon AC, Keller MB, Solomon DA, Endicott J, Coryell W, Warshaw M, Maser JD: Recurrence after recovery from major depressive disorder during 15 years of observational follow-up. Am J Psychiatry 1999, 156:1000-1006.

5. Paykel ES: Continuation and maintenance therapy in depression. Br Med Bull 2001, 57:145-159.

6. Van Loenen AC: Farmacotherapeutisch kompas, College voor Zorgverzekeringen.: ; 2003

7. Viquera AC, Baldessarini RJ, Friedberg J: Discontinuing antidepressant treatment in major depression. Harv Rev Psychiatry 1998, 5:293-306.

8. Piek E, van der Meer K, Nolen WA: Guideline recommendations for longterm treatment of depression with antidepressants in primary care-a critical review. Eur J Gen Pract 2010, 16:106-112.

9. Kaymaz N: van OJ, Loonen AJ, Nolen WA: Evidence that patients with single versus recurrent depressive episodes are differentially sensitive to treatment discontinuation: a meta-analysis of placebo-controlled randomized trials. J Clin Psychiatry 2008, 69:1423-1436.

10. van Schaik DJ, Klijn AF, van Hout HP, van Marwijk HW, Beekman AT: de HM, van DR: Patients' preferences in the treatment of depressive disorder in primary care. Gen Hosp Psychiatry 2004, 26:184-189.

11. Bockting $C L$, ten Doesschate MC, Spijker J, Spinhoven P, Koeter MW, Schene $\mathrm{AH}$ : Continuation and maintenance use of antidepressants in recurrent depression. Psychother Psychosom 2008, 77:17-26.
12. Meijer WE, Heerdink ER, Leufkens HG, Herings RM, Egberts AC, Nolen WA: Incidence and determinants of long-term use of antidepressants. Eur J Clin Pharmacol 2004, 60:57-61

13. ten Doesschate MC, Bockting CL, Koeter MW, Schene AH: Predictors of nonadherence to continuation and maintenance antidepressant medication in patients with remitted recurrent depression. J Clin Psychiatry 2009, 70:63-69.

14. Möller HJ, Riedel M, Seemüller F: Relapse or recurrence in depression: why has the cutoff been set at 6 months? Medicographia 2011, 33:125-131.

15. Frank E, Prien RF, Jarrett RB, Keller MB, Kupfer DJ, Lavori PW, Rush AJ, Weissman $\mathrm{MM}$ : Conceptualization and rationale for consensus definitions of terms in major depressive disorder. Remission, recovery, relapse, and recurrence. Arch Gen Psychiatry 1991, 48:851-855

16. Tohen M, Frank E, Bowden CL, Colom F, Ghaemi SN, Yatham LN, Malhi GS, Calabrese JR, Nolen WA, Vieta E, et al: The International Society for Bipolar Disorders (ISBD) Task Force report on the nomenclature of course and outcome in bipolar disorders. Bipolar Disord 2009, 11:453-473.

17. Hollon SD, Ponniah K: A review of empirically supported psychological therapies for mood disorders in adults. Depress Anxiety 2010, 27:891-932.

18. Jarrett RB, Kraft D, Doyle J, Foster BM, Eaves GG, Silver PC: Preventing recurrent depression using cognitive therapy with and without a continuation phase: a randomized clinical trial. Arch Gen Psychiatry 2001, 58:381-388.

19. Vittengl JR, Clark LA, Dunn TW, Jarrett RB: Reducing relapse and recurrence in unipolar depression: a comparative meta-analysis of cognitive-behavioral therapy's effects. J Consult Clin Psychol 2007, 75:475-488

20. Bockting $\mathrm{CL}$, Spinhoven P, Wouters LF, Koeter MW, Schene AH: Long-term effects of preventive cognitive therapy in recurrent depression: a 5.5-year follow-up study. J Clin Psychiatry 2009, 70:1621-1628.

21. Bockting $\mathrm{CL}$, Schene $\mathrm{AH}$, Spinhoven P, Koeter MW, Wouters LF, Huyser J, Kamphuis $\mathrm{JH}$ : Preventing relapse/recurrence in recurrent depression with cognitive therapy: a randomized controlled trial. J Consult Clin Psychol 2005, 73:647-657.

22. Bijl RV, Ravelli A: Psychiatrische morbididteit, zorggebruik en zorgbehoefte. Resultaten van de Netherlands Mental Health Survey and Incidence Study. Tijdschrift voor Gezondheidswetenschappen 1998, 76:446-57.

23. den Boer PC, Wiersma D, Van den Bosch RJ: Why is self-help neglected in the treatment of emotional disorders? A meta-analysis. Psychol Med 2004, 34:959-971.

24. Gregory RJ, Canning SS, Lee TW, Wise JC: Cognitive bibliotherapy for depression: A meta-analysis. Professional Psychology-Research and Practice 2004, 35:275-280.

25. McKendree-Smith NL, Floyd M, Scogin FR: Self-administered treatments for depression: a review. J Clin Psychol 2003, 59:275-288.

26. Van't Hof E, Cuijpers P, Stein DJ: Self-help and Internet-guided interventions in depression and anxiety disorders: a systematic review of meta-analyses. CNS Spectr 2009, 14:34-40.

27. Marrs RW: A meta-analysis of bibliotherapy studies. Am J Community Psychol 1995, 23:843-870.

28. Newman MG, Erickson T, Przeworski A, Dzus E: Self-help and minimalcontact therapies for anxiety disorders: Is human contact necessary for therapeutic efficacy? J Clin Psychol 2003, 59:251-274

29. Spek V, Cuijpers P, Nyklicek I, Riper H, Keyzer J, Pop V: Internet-based cognitive behaviour therapy for symptoms of depression and anxiety: a meta-analysis. Psychol Med 2007, 37:319-328.

30. Hunkeler EM, Meresman JF, Hargreaves WA, Fireman B, Berman WH, Kirsch AJ, Groebe J, Hurt SW, Braden P, Getzell M, et al: Efficacy of nurse telehealth care and peer support in augmenting treatment of depression in primary care. Arch Fam Med 2000, 9:700-708.

31. Mynors-Wallis LM, Gath DH, Day A, Baker F: Randomised controlled trial of problem solving treatment, antidepressant medication, and combined treatment for major depression in primary care. BMJ 2000 320:26-30.

32. First MB, Gibbon M, Spitzer RL, Williams JBW: Structured Clinical Interview for DSM-IV Axis I Disorders, Clinician Version (SCID-CV). Washington, D.C: American Psychiatric Press, Inc; 1996.

33. Joling KJ, van Marwijk HW, Piek E, van der Horst HE, Penninx BW, Verhaak P, van Hout HP: Do GPs' medical records demonstrate a good recognition of depression? A new perspective on case extraction. J Affect Disord 2011, 133:522-527. 
34. Bockting CL, Spinhoven P, Huibers MJ, Edited by Richards S, Perry M: Relapse prevention in recurrent depression using CBT, In: Relapse prevention for depression. Washington D.C: American Psychological Association; 2010.

35. Van Marwijk HWJ, Grundmeijer HGLM, Bij D, Van Gelderen MG, De Haan M, Van Weel-Baumgarten EM, Burgers JS, Boukes FS, Romeijnders ACM: NHGStandaard Depressieve stoornis (depressie) (Eerste herziening). Huisarts \& Wetenschap 2003, 46:614-633.

36. Hakkaart-van Roijen L, Van Straten A, Donker M, et al: Manual:Trimbos/iMTA Questionnaire for Costs Associated with Psychiatric Illness (in Dutch). Erasmus University: Rotterdam; 2002.

37. Morisky DE, Green LW, Levine DM: Concurrent and predictive validity of a self-reported measure of medication adherence. Med Care 1986, 24:67-74.

38. Smelt AF, van der Weele GM, Blom JW, Gussekloo J, Assendelft WJ: How usual is usual care in pragmatic intervention studies in primary care? An overview of recent trials. Br J Gen Pract 2010, 60:e305-e318.

39. Teasdale JD, Segal ZV, Williams JM, Ridgeway VA, Soulsby JM, Lau MA Prevention of relapse/recurrence in major depression by mindfulnessbased cognitive therapy. J Consult Clin Psychol 2000, 68:615-623.

40. Ma SH, Teasdale JD: Mindfulness-based cognitive therapy for depression: replication and exploration of differential relapse prevention effects. $J$ Consult Clin Psychol 2004, 72:31-40.

41. Rush AJ, Trivedi MH, Ibrahim HM, Carmody TJ, Arnow B, Klein DN, Markowitz JC, Ninan PT, Kornstein S, Manber R, et al: The 16-Item Quick Inventory of Depressive Symptomatology (QIDS), clinician rating (QIDSC), and self-report (QIDS-SR): a psychometric evaluation in patients with chronic major depression. Biol Psychiatry 2003, 54:573-583.

42. EuroQol group: EuroQol - a new facility for the measurement of health-related quality of life, Volume 16. Health Policy: The EuroQol Group; 1990:199-208.

43. Ware J Jr: Kosinski M, Keller SD: A 12-Item Short-Form Health Survey: construction of scales and preliminary tests of reliability and validity. Med Care 1996, 34:220-233.

44. Terluin B, van Marwijk HW, Ader HJ, de Vet HC, Penninx BW, Hermens ML, van Boeijen CA, van Balkom AJ, van der Klink JJ, Stalman WA: The FourDimensional Symptom Questionnaire (4DSQ): a validation study of a multidimensional self-report questionnaire to assess distress, depression, anxiety and somatization. BMC Psychiatry 2006, 6:34

45. Schwarzer R, Jerusalem M: Generalized Self-Efficacy scale, In Measures in Health Psychology: a user's portfolio. Windsor, UK: Causal and control beliefs. Edited by Weinman J, Wright S, Johnston M; 1995:35-37.

46. Krupp LB, LaRocca NG, Muir-Nash J, Steinberg AD: The fatigue severity scale. Application to patients with multiple sclerosis and systemic lupus erythematosus. Arch Neurol 1989, 46:1121-1123.

47. van der Kloot WA, Oostendorp RA: van der MJ, van den HJ: [The Dutch version of the McGill pain questionnaire: a reliable pain questionnaire]. Ned Tijdschr Geneeskd 1995, 139:669-673.

48. Larsen DL, Attkisson CC, Hargreaves WA, Nguyen TD: Assessment of client/ patient satisfaction: development of a general scale. Eval Program Plann 1979, 2:197-207.

49. American Psychiatric Association: Diagnostic and Statistical Manual of Mental Disorders. Washington DC: American Psychiatric Association; 1994.

50. Lamers LM, Stalmeier PF, McDonnell J, Krabbe PF, van Busschbach JJ: Measuring the quality of life in economic evaluations: the Dutch EQ-5D tariff. Ned Tijdschr Geneeskd 2005, 149:1574-1578.

51. Brazier JE, Roberts J: The estimation of a preference-based measure of health from the SF-12. Med Care 2004, 42:851-859.

52. Le LA, Despiegel N, Francois C, Duru G: Can discrete event simulation be of use in modelling major depression? Cost Eff Resour Alloc 2006, 4:19.

53. Penninx BW, Nolen WA, Lamers F, Zitman FG, Smit JH, Spinhoven P, Cuijpers $P$, de Jong PJ, van Marwijk HW, der Meer KV, et al: Two-year course of depressive and anxiety disorders: Results from the Netherlands Study of Depression and Anxiety (NESDA). J Affect Disord 2011, 133(1-2):76-85.

54. Paykel ES: Partial remission, residual symptoms, and relapse in depression. Dialogues Clin Neurosci 2008, 10:431-437.

55. Van Voorhees BW, Paunesku D, Kuwabara SA, Basu A, Gollan J, Hankin BL, Melkonian S, Reinecke M: Protective and vulnerability factors predicting new-onset depressive episode in a representative of U.S. adolescents. $J$ Adolesc Health 2008, 42:605-616.

56. Geerlings SW, Twisk JW, Beekman AT, Deeg DJ: van TW: Longitudinal relationship between pain and depression in older adults: sex, age and physical disability. Soc Psychiatry Psychiatr Epidemiol 2002, 37:23-30.
57. Skapinakis $P$, Lewis $G$, Mavreas $V$ : Temporal relations between unexplained fatigue and depression: longitudinal data from an international study in primary care. Psychosom Med 2004, 66:330-335

58. Segal ZV, Kennedy S, Gemar M, Hood K, Pedersen R, Buis T: Cognitive reactivity to sad mood provocation and the prediction of depressive relapse. Arch Gen Psychiatry 2006, 63:749-755.

59. Hakkaart-van Roijen L, Tan SS, Bouwmans CAM: Handleiding voor kostenonderzoek. Rotterdam: Instituut voor Medical Technology Assessment iov CZV; 2010

60. Oostenbrink JB, Koopmanschap MA, Rutten C: Standardisation of Costs. Adis International: The Dutch Manual for Costing in Economic Evaluations; 2002.

61. Koopmanschap MA, Rutten FF, van Ineveld BM, van Roijen L: The friction cost method for measuring indirect costs of disease. J Health Econ 1995 14:171-189.

62. Boston RC, Sumner AE: STATA: a statistical analysis system for examining biomedical data. Adv Exp Med Biol 2003, 537:353-369.

63. Cohen SB: An evaluation of alternative PC-based software packages developed for the analysis of complex survey data. The American Statistician 1997, 51:285-292.

64. Van Buuren S, Oudshoorn CGM: Multivariate imputation by chained equations. TNO Preventie en Gezondheid: MICE V1.0 user's manual. Leiden; 2000.

65. Thompson SG, Barber JA: How should cost data in pragmatic randomised trials be analysed? BMJ 2000, 320:1197-1200.

66. Fenwick E, O'Brien BJ, Briggs A: Cost-effectiveness acceptability curves facts, fallacies and frequently asked questions. Health Econ 2004, 13:405415

67. Hoch JS, Rockx MA, Krahn AD: Using the net benefit regression framework to construct cost-effectiveness acceptability curves: an example using data from a trial of external loop recorders versus Holter monitoring for ambulatory monitoring of "community acquired" syncope. BMC Health Serv Res 2006, 6:68.

doi:10.1186/1471-244X-12-59

Cite this article as: Biesheuvel-Leliefeld et al:: Cost-effectiveness of nurseled self-help for recurrent depression in the primary care setting: design of a pragmatic randomised controlled trial. BMC Psychiatry 2012 12:59.

\section{Submit your next manuscript to BioMed Central and take full advantage of:}

- Convenient online submission

- Thorough peer review

- No space constraints or color figure charges

- Immediate publication on acceptance

- Inclusion in PubMed, CAS, Scopus and Google Scholar

- Research which is freely available for redistribution 